\title{
Perplejidades, casos y aprendizaje: elaborando un saber sobre las instituciones
}

PhD. Myriam Southwell*

\begin{abstract}
Este artículo explora algunas tensiones de la educación como problema y su formato institucional escolar. Asimismo, se aborda aquí el impacto de la utilización de la metodología de casos como modo de abordaje de las complejas situaciones institucionales de las escuelas. Así, se hace referencia a un recorrido realizado recientemente en el Diploma en Planificación y Gestión Educativa con relación a la metodología de análisis de casos. La construcción de casos ha sido un modo de interpretar la entrada de lo nuevo en nuestros centros, de modo que nos posibilite ubicarnos en esa zona entre lo conocido y lo "por descubrir". Allí, en la implicación de búsqueda que esa metodología conlleva, el uso de las escenas no intenta plasmar imágenes precisas, sino movimientos hacia aquello por descubrir. En este sentido, los elementos componentes de la descripción son epifenómenos que nos permiten indagar la presencia y profundidad de aspectos individuales y sociales, y su puesta en acto en los ámbitos institucionales que constituyen nuestra preocupación.
\end{abstract}

Un reciente trabajo de Graciela Frigerio (2001) al que haremos referencia reiteradamente en este artículo, nos recuerda que trabajar en educación, pensar sobre ella, comprender y hacer sus instituciones, constituye lo que Ansart denomina una de las pasiones políticas de las democracias. Es sabido que la educación y sus instituciones han producido y solicitado acuerdos y contiendas. Siempre han estado presentes en los discursos de las políticas; siempre han sido atravesadas por las tensiones entre pasado y futuro, entre lo viejo y lo nuevo, entre el reconocimiento de las diferencias y un horizonte de igualdad. Es obvio, entonces, que la educación no admite las reducciones tecnócratas y lucha por escapar del encapsulamiento que le propone la lógica del mercado, no se deja subsumir en un manojo de disciplinas y es siempre algo más que una "necesidad real". La educación excede a lo escolar y, aunque allí se le da curso, "no se limita a una cuestión de estructuras y desborda lo curricular"1.

De este modo lo educativo ha sido siempre, parte fundamental de la construcción social y de las subjetividades que en ella se despliegan. El tratamiento institucional del enigma en relación con el conocimiento -el enigma ligado a la transmisión de lo existente y a la producción de lo nuevo-, así como el tejido del lazo social es su meta. Tramita ambas cuestiones de modos diversos, a partir de abordar conocimientos disciplinares, distribuir capital cultural, socializar distintos saberes (saberes para vivir, saberes para pensar, saberes para trabajar, saberes para crear), diseñar formas organizacionales; integrar actores diversos; recordar mitos, instituir ritos, ofrecer inscripciones y filiaciones simbólicas; tejer vínculos (con lo desconocido, con el conocimiento, con los otros, con el mundo), así como de institucionalizar la relación con la ley estructurante de lo social. La educación desborda lo escolar y a las "formas escolares", esto es, al modo en que los tiempos, las historias y los actores resuelven institucionalizarla (Frigerio, 2001). 
Por ello, podemos tomar la denominación de borde, para remitir a las poco delimitadas zonas de las relaciones entre las instituciones y sus contextos, ya que como lo mencionaremos repetidas veces aquí, estos límites se vuelven más que borrosos en numerosas ocasiones. Por ello, nos resulta más productivo tomar la idea de bordes, como aquellas características que son contextuales e internas simultáneamente.

En ese borde, no sabemos aún la características que nos revelarán las escenas escolares del nuevo siglo y sobre ellas hemos trabajado recurrentemente en clase para pensar nuestros casos. Los casos han sido modos que nos permitieron interpretar la entrada de lo nuevo en nuestras instituciones; tenemos actores aferrados y viejas formas; otros preocupados por cambiar modos, conscientes del sufrimiento que provocan; muchos no quieren decir no a lo que vendrá: considerar la producción de lo nuevo con el saber de la experiencia y los aportes de una crítica, para conocer de modo más honesto a las instituciones que habitamos, es el objetivo de esta propuesta metodológica.

\section{Bordeando nuestros casos}

En ocasiones algunas escenas de nuestras escuelas de hoy muestran bordes de una edad que no se deja capturar en un grupo etario: el borde en que el límite toma la forma de violencia, desempleo, distintas formas de amenaza, o adopta nombre de SIDA, o como suscripción a una adicción, desvanecimiento de formas de protección y justicia, etc. (Frigerio, 2001).

Podemos hipotetizar que en las escenas de un nuevo tiempo sería deseable que la interlocución -en sus diferentes formas- entre un profesor y un estudiante, entre un maestro y un alumno no se vea interrumpida ni sustituida. La cuestión del tiempo, del tiempo futuro y del tiempo por venir (haciendo énfasis aquí en la posibilidad que el sujeto y las sociedades tienen de hacer venir, como resultado de su obra, un tiempo distinto) remite a otra aproximación a un borde. ${ }^{2}$ Nuestro énfasis en la recuperación de escenas de las instituciones tiene en cuenta que ellas no se limitan a un presente, ponen en juego la vida de cada sujeto en el territorio de lo social y en el mundo interno, en un terreno de extraterritorialidad. ${ }^{3}$

El pensamiento y la producción de saberes como centro nuclear del trabajo de enseñar y aprender, alcanza sus mayores desafíos en el borde entre lo conocido y lo por descubrir y/o crear. Ese borde ha sido recorrido recientemente por nosotros en el Diploma en Planificación y Gestión Educativa con relación a la metodología de análisis de casos, buscando que los casos nos permitieran ubicarnos en esa zona entre lo conocido y lo "por descubrir". Allí, en la implicación de búsqueda que esa metodología conlleva, el uso de las escenas no intenta plasmar imágenes precisas sino explorar aquello por descubrir.

\section{Casos y construcción de sentido: cuestiones metodológicas}

Relata Frigerio que antiguamente, en la época del origen del teatro griego, tiempos de elaboración de problemáticas colectivas y subjetivas que daban lugar a tragedias y mitos (mitos y tragedias que venían a presentar el alma humana), las escenas (narradas, actuadas, relatadas) conllevaban la intención de una conmoción en la comprensión del espectador. En esto, los relatos poseían un carácter "pedagógico", se presentaba un saber no sabido, un saber renegado, ofreciendo condiciones de posibilidad para una elaboración. Los relatos encontraban (o desplegaban) en la secuencia de una composición, las razones y sinrazones de lo que acontecía. Cada personaje daba cuenta de su historia inscripta en una genealogía, que no omitía la 
explicitación de los lugares sociales. Cada escena tenía a cargo de distintos actores su argumento y su contra-argumento; exponer unos y otros, ocasionalmente en forma de diálogo como gustaban los primeros filósofos era la estrategia para que, lo que surgiera de un encuentro tuviera una oportunidad de consistencia y verdad. Pequeños detalles descriptivos -eran pistasdaban información necesaria para saber lo que estaba en juego. Lo pequeño, era significativo, iba más allá de lo anecdótico y siempre venía a cuenta de un sentido sobre-determinado en la escena (Frigerio, 2001).

En este sentido hemos situado escenas y casos; los elementos componentes de la descripción son epifenómenos que nos permiten indagar la presencia y profundidad de aspectos individuales y sociales y su puesta en acto, en los ámbitos institucionales que constituyen nuestra preocupación.

Transformar una descripción acotada en un conjunto de elementos de indagación, o transformar un relato en un caso, implica convertir una experiencia en aprendizaje, concepto éste que es central de lo educativo y que no debe perderse de vista tampoco desde la perspectiva de la gestión. Esta transformación de un relato en un insumo de investigación requiere contar con una pluralidad de elementos, voces y perspectivas.

En términos metodológicos una escena recortada requiere, también, prudencia, la escena nos dirá sobre lo que un actor considera significativo para ser destacado, lo que es sin duda importante pero no suficiente para construir un saber. Los pasos subsiguientes para elaborar una conceptualización o construir teoría, remiten a la disponibilidad de datos pertinentes. De este modo vuelve a cobrar sentido la denominación de epifenómeno, que despierta la necesidad de preguntas de investigación que permitan explicar el surgimiento de esa manifestación, y los fenómenos concurrentes para ella.

Resumiendo, podríamos decir que la observación (de escenas, por ejemplo) habilita el acceso a elementos que posibilitan mejorar el conocimiento de las instituciones, y aporta pruebas empíricas que permiten la demostración o la revisión de las hipótesis de trabajo. Es decir, la observación tiene el rol de proponer una eventual ruptura con lo que podríamos llamar "saber inmediato" (es decir aquel que constituye y se constituye con los aportes del sentido común, las pre-nociones y del sentido común sabio) a través de un cuerpo de preguntas e hipótesis problematizadoras en las cuales la observación va a tomar sentido. Se trata de establecer la necesaria relación entre la experiencia personal y la objetivación (no estamos diciendo objetividad); objetivación que conlleva la explicitación del marco de referencia del observador y la de su posición institucional. Algunos autores nos recuerdan que es necesario tener en cuenta que, cuando el observador (o el narrador) es un miembro de la institución, en tanto actor, está inmerso en ella y en el sistema al que la misma pertenece. Comprender el modo en que la institución permea al observador es tan importante como dar cuenta del marco de referencia que constituye su punto de mira, su grilla para decodificar e interpretar. Cuando la observación es hecha por alguien externo a la institución, lo que se vuelve necesario es explicitar el marco desde el cual realiza la misma, dejar claro la demanda de la institución (a sabiendas de que nunca es ella la que formula una demanda sino un conjunto de sus miembros). También es necesario detenerse a considerar el destinatario de la elaboración que se lleve a cabo a posteriori de la observación. Así, podría darse el caso de un observador que en el marco de una investigación, no solicitada por el centro, elaborase un trabajo sobre éste cuyos destinatarios fueran sus pares y no todos los miembros de la institución. Podría ocurrir que la observación fuera llevada a cabo por un investigador, consultor, consejero, asesor, a solicitud de la misma y que el trabajo tenga como condición presentarse ante el conjunto de los actores institucionales. 
Ninguna de estas alternativas carece de efectos sobre el trabajo que se lleve a cabo. En todos los casos se hace necesario asegurar una ida y vuelta constante entre los hechos institucionales objetivados y el universo de imágenes, representaciones, percepciones y andamiajes conceptuales previos que configuran los escenarios institucionales. Esta ida y vuelta, aseguraría que la institución pueda ser comprendida y explicada por su mismo sistema y no exclusivamente por las singularidades individuales. Esto no significa ignorar el sentido institucional de las singularidades individuales, de hecho, es a ellas a quienes debemos numerosas iniciativas. Son los actores, haciendo uso de sus márgenes de libertad y ampliándolos, los que promueven las acciones que dan vida a la institución (Frigerio, 2001).

Como han expresado Frigerio y Poggi, es necesario pasar del saber no sabido a un saber a sabiendas sobre las instituciones en las que llevamos a cabo nuestra actividad enseñante. Dicho saber no debiera renegar de las actividades de una gestión si se entiende por tales las prácticas de macro y micro política educativa. El problema surge, en los sistemas y en las instituciones cuando la concepción de gestión se simplifica, se reduce a un tema organizacional o se vuelve banalización administrativa o administración burocrática ${ }^{4}$.

En el transcurso de este trabajo hemos hecho repetidas referencias al hecho de que el saber sobre las instituciones es un saber colectivo, es decir, por definición compartido. Esa afirmación supone también un aprendizaje colectivo para desaprender culturas burocráticas, individualistas, competitivas, restaurar la confianza socavada por autoritarismos y exclusión. Nuevamente siguiendo lo planteado por Frigerio- evocamos aquí la textura del borde, en la constatación de los débiles límites en "afueras" y "adentros", entre contextos que se vuelven textos cotidianamente en cada concreción institucional. Desde la perspectiva conceptual que estamos presentando, no podríamos avanzar en un diálogo productivo dentro de una escena institucional si los actores no están presentes ni representados, sin una masa crítica de datos, sin profundizar el contexto de descubrimiento (conjunto de factores históricos, sociológicos, económicos, psicológicos, cognitivos que favorecen o inhiben la producción de conocimientos) y sin reconstruir el contexto de justificación. Bien vale construir un conjunto de proposiciones, agenda de discusión, a modo de ensayo, puestas a disposición para intentar trabajar simultáneamente sobre cuestiones metodológicas, andamiajes conceptuales y prácticas institucionales.

\section{Casos y abordajes}

Existen problemáticas compartidas por las distintas instituciones a las que hemos aludido durante este año de trabajo; aunque son comunes, en cada una se perfilan con distintos matices. Aun cuando hay diferentes maneras, el elemento común es la preocupación y necesidad promover formas para que siga habiendo escuela -en el sentido más generoso del términopara todos ( $y$ ese todos incluye a aquellos cuya realidad circundante se ha modificado profundamente).

Por ejemplo, un elemento central que ha aparecido recurrentemente es el carácter estructurante de la presencia o ausencia del mandato familiar acerca de la escolaridad (mandato que a veces parece estar en crisis), dando a suponer que en algunas instituciones opera una cierta coincidencia entre mandato familiar, biografía escolar y proyecto institucionalizado. Muchas veces también se nombra el peso que pueden adquirir las representaciones familiares sobre una escuela en particular, y la disposición que las familias desarrollan en relación con él. En otros casos el mandato de escolaridad parece surgir del vínculo que la institución promueve con los alumnos (Frigerio, 2001). Es la institución la que crea pertenencia y permanencia del estudiantado, la experiencia escolar parece ofrecer un sentido en sí. El sentido de ir a la escuela lo estaría proporcionando la propia escuela.

\section{8 - Universidad ORT Uruguay}


Muchas de las narraciones que encontramos habitualmente, por ejemplo en espacios de formación como el que ofrece el Instituto de Educación de la Universidad ORT, hacen mención a nuevas figuras del estudiantado y a nuevas configuraciones familiares. En todos los casos el "oficio de estudiante" conserva algunos rasgos "familiares" (para escuelas y educadores) pero también ha incorporado componentes de angustia que no eran propios de otros tiempos y una preocupación por el futuro en el marco de un presente poco prometedor. Ausencia de promesas de un futuro mejor, desaliento, resignación y angustia quizá expliquen el por que nuestros casos -en ocasiones- dan cuenta de instituciones que alojan y cobijan a una adolescencia "desconcertante". Adolescencia sometida, a los apurones, a una anticipada y particular adultez, impuesta por los requerimientos de economías restringidas; la crisis de una cultura que ha diluido los referentes adultos, el abandono de las políticas públicas (o su sustitución por formas alternativas o asociadas de asistencialismo). Esta adolescencia desconcertante es la que muestra el límite de las actuales formas escolares y también, pensando en ellas es que las viejas instituciones se transforman a sí mismas tratando de construir un sentido para la experiencia escolar. Ante todas esas problemáticas, debe subrayarse que la responsabilidad de lo escolar sigue siendo la de la emancipación intelectual. En estos tiempos, buena parte de las escuelas hacen de la solidaridad un eje de trabajo, presentan alternativas a la exclusión y buscan modos democratizadores de redefinir su especificidad. Parece ser evidente que en las escuelas que se piensan a sí mismas como espacios de reconocimiento, es donde la vida del otro se significa; es decir, resultan ser instancias de buenas preguntas (sin respuestas presabidas o pre-armadas), preguntas sobre lo desconcertante, sobre los desafíos y las resistencias, sobre las responsabilidades compartidas y las responsabilidades específicas. Estos elementos resignifican la noción de obligación, en términos de responsabilidad y de no resignación (Frigerio, 2001).

¿Cuáles pueden ser los abordajes desde la institución? Enfatizaremos aquí dos elementos conceptuales que pueden alcanzar luego muy diversos modos de concreción institucional. Hablaremos de la necesidad de "recibir a los nuevos y a lo nuevo" y de la recuperación de la función de transmisión.

La escuela tiene -siguiendo a Laurence Cornu ${ }^{5}$ - un deber de hospitalidad, o bien, como lo plantea Hannah Arendt, "la educación comporta hacia los recién llegados (como los nuevos sujetos del viejo mundo) simultáneamente un rito de iniciación y la oportunidad de lo nuevo, filiación en su sentido más amplio, es decir: un componente insoslayable de la construcción social y co-productora de subjetividad"6. Por esas características la educación y la escolarización cumplen funciones de transmisión social y también de reparto y distribución.

Si educar es un deber de hospitalidad, cada una de las narraciones de casos de las que hemos hecho uso, da cuenta de cómo la institución recibe, aloja y hospeda a las nuevas generaciones y también de cómo se tramita la hostilidad (hostilidad social, familiar, individual) agudizada en tiempos de producción y la exclusión, que permanentemente jaquea el deber de hospitalidad y el derecho de protección que debería ser garantizado para todos. Podemos pensar que hoy algunas instituciones intentan compensar la ausencia del deber de hospitalidad que debería estar a cargo de todas las políticas y del conjunto de la sociedad. ¿Hay modo de alojar al nuevo, de hospedarlo, eludiendo el diálogo? Si educar es tarea de filiación e inscripción, es necesario tener en cuenta que el sujeto también necesita pertenecer a un proyecto de iniciación al saber, para dar un sentido a su existencia y crear y recrear, permanentemente los procesos de participación en la producción de la cultura, propia de una sociedad de humanos. 
A la vez, si educar es volver acción el imperativo de reparto, se hace necesario consignar que reparto no es cualquier distribución, ni distribución de cualquier cosa. Podríamos decir que reparto no es caridad, ni asistencialismo, mucho menos demagogia; reparto es justicia, es distribución de conocimiento y de reconocimiento (Frigerio, 2001).

\section{Viejos y nuevos desafíos}

Hay un elemento que aunque no haya sido mencionado como tal, está presente en todos los casos que hemos analizado directa o indirectamente: la función de transmisión. La noción de transmisión es una noción ambigua que remite a distintos significados. En un registro, alude a la relación entre adultos y niños/jóvenes que puede verse erosionada por efecto de los cambios producidos en estas últimas décadas en las instituciones familiares y educativas; es decir, cambios en los vínculos básicos relacionados con la crianza y la educación. En otro registro, la noción de transmisión alude -en los procesos macrosociales- a la relación compleja entre Estado, mercado y sociedad civil en un escenario nacional en el que los mandatos modernos -entre otros el referido a la educación de las nuevas generaciones- están siendo modificados y alterados en lo que hace tanto a las instituciones intervinientes en tal tarea, como a la toma de decisiones públicas y a las responsabilidades sociales que tal tarea implica.

El concepto de transmisión, según Kaes, está connotado por una dirección del tiempo; una transmisión es siempre un proceso que se realiza en la duración, supone una inscripción temporal: la transmisión ha sido definida como un transporte en el tiempo, por una prolongación, en la cual la educación ha operado como un soporte privilegiado para la construcción de una memoria y -en especial- de una memoria nacional ${ }^{7}$. Debray distingue la idea de transmisión de la de comunicación, caracterizada por un transporte en el espacio. A la transmisión le adjudica un carácter regulador y ordenador por un triple alcance: material, diacrónico y político ${ }^{8}$. Sin embargo, la educación en sentido amplio se ha visto alterada en estas décadas recientes por la combinación y tensión entre distintas experiencias del tiempo, que han hecho estallar ese tiempo lineal y progresivo del proceso del proyecto educacional actual. Es decir, la transmisión cultural reciente se configuró sobre un sentido del tiempo que se basaba en la dinámica del progreso moderno, que conduciría a los estados nacionales, al desarrollo científico, a la conformación de una sociedad y a la participación ciudadana; esa idea de transmisión, por lo tanto, adquiere nuevos sentidos cuando debe considerar las experiencias del tiempo presente.

Si estas complejas y diversas experiencias del tiempo, ponen en jaque la dirección del tiempo de la transmisión moderna y generan cuestionamientos profundos a la función educativa -más aun en un contexto en el que Estado y sociedad civil sufren una metamorfosis inédita-, ello no debe eliminar el hecho de que toda generación que ve la luz, hace a un mundo que desconoce y que invariablemente demanda de los adultos una tarea de transmisión del sentido de ese mundo y de las formas de incorporarse en él. Como ha señalado Arendt "sin testamento o, para sortear la metáfora, sin tradición -que selecciona y denomina, que transmite y preserva, que indica dónde están los tesoros y cuál es su valor-, parece que no existe continuidad voluntaria en el tiempo y, por tanto, hablando en términos humanos, ni pasado ni futuro (...)"9. Es un problema de la transmisión -y en particular de la transmisión cultural llevada adelante por las instituciones educativas-, la posibilidad de construir un relato que dé cuenta de la continuidad en el tiempo, pero también es problema de la escuela registrar la discontinuidad del tiempo, ése que convierte a los alumnos en seres diversos de los adultos, otros, en alguna medida desconocidos por vivir en un presente que tiene características inéditas para el adulto. Toda generación joven se constituye a partir de una diferencia, pero de una diferencia que se modula 
luego de una toma de posición más o menos explícita, condescendiente, contestataria o indiferente, frente a lo recibido de la generación anterior ${ }^{10}$. La filiación generacional que la transmisión supone, desafía las decisiones que el sistema educativo ensaya día a día. Esa transmisión no puede predecir qué hará la nueva generación con ella, en todo caso producirán una escritura propia, un proyecto, una tarea que será -en alguna medida- una reescritura, pero también una creación singular.

En este contexto, debemos recordar que nuestras prácticas como educadores, se desarrollan reinterpretando mandatos fundacionales, a la vez que transmitiendo y reinscribiendo la historia en el diseño de un futuro. En este sentido, hemos intentado "pasar lista" rápidamente de algunos desafíos que se les presentan a nuestras instituciones -aquellas que hemos buscado interpretar a través de nuestros casos-. Ejemplos de ello son los desafíos de incorporar la diferencia, vinculada a la alteridad sin la cual no se construye un "todos" plural, por un lado; por otro, la necesidad de vivificar la función de transmisión y de construcción de la cultura.

Desde nuestra perspectiva, esto está en juego en las narraciones que hemos recordado hoy y utilizado en clase y en documentos, esto es lo que está en juego, los modos en los que las instituciones pueden interrogarse a sí mismas para aprender e intervenir sobre ellas. Esta búsqueda de saber se produce a la vez que procuramos que nuestras instituciones se preocupen por el modo de hospedar a los nuevos y a lo nuevo, alojar el por-venir y darle la posibilidad de que no sea reproducción ni repetición ${ }^{11}$.

Gestionar una institución de formación implica, entre muchas otras cosas, poder hacerse de un buen panorama de la realidad que nos atraviesa; reflexionar y diseñar estrategias para operar en ella. Esto produce una oportunidad de estar al borde de los registros del saber (conocido/desconocido) y de hacer de ese borde una frontera transitable para quienes buscamos gestionar la institución.

Sin lugar a dudas, una pregunta de la que apenas hemos sondeado respuestas, queda abierta, ya que es una de esas preguntas permanentes para cotejar la decisiones cotidianas: ¿cómo construir un espacio educativo que sea escenario para modular una experiencia común a distintas generaciones, en contextos de cambio cultural y educativo acelerado? A ella se suman otras preguntas similares: ¿cuáles son los desafíos para que las instituciones de hoy sigan siendo un lugar de alojar a los nuevos? ¿Cómo pueden, nuestros proyectos de trabajo, incluir modos de recibir e interpretar "lo nuevo" sin que la incertidumbre nos inhabilite para actuar?

\section{Bibliografía y notas}

${ }^{1}$ Frigerio, G. "Los bordes de lo escolar" en BIRGIN A. y DUSCHATZKY S., 2001. ¿Dónde está la escuela?, Buenos Aires: Editorial Manantial.

2 Siguiendo la afirmación de Frigerio (op.cit).

${ }^{3}$ Steiner, G. 2000. Extraterritorialidad. Ensayos sobre literatura y revolución del lenguaje. AH Ed. 2000. Citado por Frigerio (op.cit).

${ }^{4}$ Frigerio, G. y Poggi, M. 1998. De aquí y de allá. Textos sobre las instituciones educativas. Buenos Aires: Editorial Kapelusz. 
${ }^{5}$ Seminario Cornu/Frigerio- Febrero 2001. Facultad de Ciencias de la Educación. Universidad Nacional de Entre Ríos.

${ }^{6}$ Jorge Larrosa toma estas formulaciones de Arendt para desarrollar una conceptualización acerca del enigma de la infancia. Larrosa, J. 2000. Pedagogía Profana. Estudios sobre lenguaje, subjetividad, formación. Buenos Aires: Ediciones Novedades Educativas. Universidad Central de Venezuela.

${ }^{7}$ Kaes, R. 1996. Transmisión de la vida psíquica entre generaciones. Buenos Aires: Amorrortu.

${ }^{8}$ Debray, R. 1997. Transmitir. Buenos Aires: Editorial Manantial.

${ }^{9}$ Arendt, H. 1996. Entre el pasado y el futuro. Ocho ejercicios sobre la reflexión política. Barcelona: Península.

${ }^{10}$ Sobre estos aspectos recomendamos el trabajo de Jacques Hassoun. 1996. Los contrabandistas de la memoria. Buenos Aires: Ediciones de la Flor.

${ }^{11}$ Estamos utilizando nuevamente los aportes de Graciela Frigerio.

* PhD. en Educación, Universidad de Essex, Inglaterra. Magister en Ciencias Sociales, Facultad Latinoamericana de Ciencias Sociales (FLACSO). Licenciada en Ciencias de la Educación, Universidad Nacional de La Plata, Argentina. Docente y tutora, Instituto de Educación. 